PAPER

\title{
Alzheimer disease and pre-emptive suicide
}

\author{
Dena S Davis
}

\begin{abstract}
Correspondence to Dr Dena S Davis, Department of Religion Studies, Lehigh University, 9 W. Packer Avenue, 240 Maginnes Hall, Bethlehem, PA 18015-3075, USA; Dsd311@lehigh.edu
\end{abstract}

Received 15 August 2012 Revised 10 May 2013

Accepted 7 June 2013 Published Online First 10 July 2013

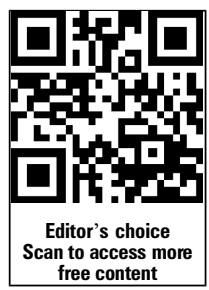

\section{Linked}

- http://dx.doi.org/10.1136/ medethics-2013-101615

\begin{abstract}
There is a flood of papers being published on new ways to diagnose Alzheimer disease (AD) before it is symptomatic, involving a combination of invasive tests (eg, spinal tap), and pen and paper tests. This changes the landscape with respect to genetic tests for risk of $A D$, making rational suicide a much more feasible option. Before the availability of these presymptomatic tests, even someone with a high risk of developing $A D$ could not know if and when the disease was approaching. One could lose years of good life by committing suicide too soon, or risk waiting until it was too late and dementia had already sapped one of the ability to form and carry out a plan. One can now put together what one knows about one's risk, with continuing surveillance via these clinical tests, and have a good strategy for planning one's suicide before one becomes demented. This has implications for how these genetic and clinical tests are marketed and deployed, and the language one uses to speak about them. The phrase 'there is nothing one can do' is insulting and disrespectful of the planned suicide option, as is the language of the Risk Evaluation and Education for Alzheimer's Disease (REVEAL) studies and others that conclude that it is 'safe' to tell subjects their risk status for AD. Further, the argument put forward by some researchers that presymptomatic testing should remain within research protocols, and the results not shared with subjects until such time as treatments become available, disrespects the autonomy of people at high risk who consider suicide an option.
\end{abstract}

Someday you will not have to be demented to be diagnosed with Alzheimer's disease.

Jason Karlawish, MD.

\section{PROLOGUE}

Still Alice is a gripping novel by neuroscientist Lisa Genova, describing the experience of dementia from the perspective of the victim. Alice Howland is an eminent professor of psychology in her 50's when puzzling symptoms lead to the diagnosis of early-onset Alzheimer disease (AD). She doesn't want to leave life too early, but she also doesn't want to sink into total dementia. She obtains a bottle of sleeping pills and sets up a failsafe method, where her faithful smartphone buzzes once a day to remind her to take a simple quiz. The message directs her that when she is no longer able to remember the names of her children or the current month of the year, she should go directly to her computer, open a folder marked 'Butterfly', and do what it tells her. Over the next 2 years, she responds to the quiz but fails to notice that she is answering the questions at first with less specificity and later with wrong responses. Eventually the smartphone is ruined when she leaves it in the freezer, and it is not replaced. One day she is randomly opening folders on her computer when she happens upon 'Butterfly'. She is astounded to find there a letter addressed to her from her former self. Among general messages of love and reassurance, she reads:

You wrote this letter to yourself when you were of sound mind.... You can no longer trust your own judgment, but you can trust mine, your former self. You before Alzheimer's took too much of you away....I love you and I'm proud of you, of how you've lived and all that you've done while you could. Now, go to your bedroom. Go to the black table next to the bed, the one with the blue lamp on it. Open the drawer to that table. In the back of the drawer is a bottle of pills. The bottle has a white label on it that says FOR ALICE in black letters. There are a lot of pills in that bottle. Swallow all of them with a big glass of water. Make sure you swallow all of them. Then, get in the bed and go to sleep.

Go now, before you forget. And do not tell anyone what you're doing. Please trust me.

Love,

Alice Howland ${ }^{1}$

Although Alice tries to comply with the instructions, she forgets what she is meant to do by the time she reaches her bedroom. She wishes she could print out the letter, but has forgotten how to use the printer. Eventually, she becomes distracted by her husband's voice and forgets the whole thing.

\section{INTRODUCTION}

The thesis of this article is that suicide is one reasonable response to impending dementia, whether from $\mathrm{AD}$ or some other cause. For people so inclined, however, a major barrier has been the difficulty of pinpointing a time to act: not so early as to lose many good years, but not so late that the subtle onset of dementia robs one of the ability to appreciate the situation and to act in accordance with one's goals. Recent advances in the creation of biomarkers that diagnose impending, presymptomatic dementia are an important scientific development that potentially lowers this barrier and invites revisitation of this complex topic. Of prime importance is whether people will have access to these biomarkers and the information they produce, or whether misplaced paternalism will prompt healthcare professionals to attempt to keep control over these new modalities. As President Obama unveils an ambitious new agenda, titled 'Brain Research 
Through Advancing Innovative Neurotechnologies', which includes attention to the ethical implications of advances in neuroscience, it is important that all ethical perspectives be part of the discussion.

I proceed in the following fashion. First, I summarise the reasons why many people find an earlier death through suicide preferable to a longer life that includes dementia. Second, I discuss some of the barriers to ending one's life early in order to escape dementia. Third, I explain the difficulties engendered by the 'predictive challenge'. Prediction is crucial for dementing diseases because, unlike other diseases such as cancer, a person cannot wait until the disease takes hold to decide to end her life; once the disease holds sway it is already too late to act. Fourth, I describe the new array of biomarkers that hold out the promise of predicting the onset of dementia while one still has the capacity to act. Finally, I argue that gatekeepers such as researchers, clinicians and policymakers need to acknowledge the option of pre-emptive suicide when deciding how to allocate resources, when to 'return results' to research volunteers and so on.

\section{WHY DO WE FEAR DEMENTIA?}

People who express interest in rational suicide usually do so from a mixture of motivations related to autonomy (distaste for a life of dependence), non-maleficence (a wish to avoid burdening others) and beneficence (preservation of assets to hand on to others). From the perspective of the non-demented person, impending dementia threatens one's most precious interests in at least three ways. Firstly, many people wish to conserve their assets to use in ways consistent with their long-held values, for example, to endow a scholarship fund at their alma mater. It is important to remember that the average span between diagnosis and death for someone with $\mathrm{AD}$ is 8 years, with some people living as long as 20 years. During the final stages of the disease, the person usually needs round-the-clock care, which can be ruinously expensive. As one person memorably wrote in his advance directive, 'Just because I may suffer from a disease that robs me of my cognitive capacity, that doesn't mean that I've made a decision that the prime beneficiaries of my estate shall then become hospitals, nursing homes, doctors, or leasers of medical devices'. ${ }^{2}$

Secondly, it is common for people to take joy and pride in handing on some assets to their children or grandchildren. Aside from material assets, people may wish to avoid burdening grown children with their care; this might be especially true of the feminists among us, as caregiving so often falls disproportionately on women. ${ }^{3}$ Most $\mathrm{AD}$ care in the early stages is handled 'informally' by family members, whose own health, finances and quality of life often suffer dramatically. ${ }^{4}$

Those of us who currently enjoy a warm relationship with our children may be horrified to imagine a time when we become simply 'the problem'. 'I do not know how death panels ever got such a bad name. Perhaps they should have been called deliverance panels. What I would not do for a fair-minded body to whom I might plead for my mother's end. ${ }^{5}$

Of course, there is a whole literature on the 'grace' of accepting and giving care. Gilbert Meilaender makes this case in an essay half-humorously titled 'I Want to Burden My Loved Ones' (1991):

Is this not in large measure what it means to belong to a family: to burden each other-and to find, almost miraculously, that others are willing, even happy, to carry such burdens? Families would not have the significance they do for us if they did not, in fact, give us a claim upon each other. At least in this sphere of life we do not come together as autonomous individuals freely contracting with each other. We simply find ourselves thrown together and asked to share the burdens of life while learning to care for each other. ${ }^{6}$

Others of us feel that even the bonds of family do not dissolve our interests in independence and autonomy, especially if the dependence at issue is not merely a temporary state. In an article baldly titled 'Is There a Duty to Die?' John Hardwig develops a moral argument for a duty to die when a confluence of factors makes the burden on one's loved ones overwhelming, compared to the loss to oneself of some continued period of time in a debilitated condition. Hardwig gives an example of an elderly mother who chooses aggressive life-prolonging treatment in the face of congestive heart failure. Her 55 -year-old daughter, her only remaining family, caregiver and primary source of financial support, dutifully cared for her mother, but in the process lost her savings, home, job and career. ${ }^{7}$ Hardwig further reasons that, given a duty to die in some circumstances, that duty is not extinguished because one has become incompetent. Therefore, because other people are not likely to help him to carry out this duty once he has become incompetent, he concludes that 'my obligation may be to die while I am still competent, before I become unable to make and carry out that decision for myself. Surely it would be irresponsible to evade my moral duties by temporizing until I escape into incompetence. And so I must die sooner than I otherwise would have to'. ${ }^{7}$ Hardwig is almost subversive in upending the usual view that rational suicide is selfish, individualistic, autonomy driven and dismissive of family and community. Rather, he takes the concern for family and community we see in Meilaender, above, and in feminists pushing an 'ethic of care', and turns it upside down, arguing that refusal to brook the possibility of a duty to die comes from an American 'individualistic fantasy' that leads us to 'imagine that our lives are separate and unconnected..."7

Thirdly, and most importantly, people have a strong interest in ending their lives with a final chapter that is consonant with the narrative as a whole. Ethicists such as Meilaender may argue that it is arrogant and delusional, autonomy run amok, to imagine that one can control the course of one's life. For Meilaender, 'morality consists in large part in learning to deal with the unwanted and unexpected interruptions to our plans'. 6 Certainly, there is much one simply has to accept. But that should not stop those of us who wish to do so from fashioning our best outcome from the cards we are given to play. As Ronald Dworkin says, 'We worry about the effect of [our] life's last stage on the character of [our] life as a whole, as we might worry about the effect of a play's last scene or a poem's last stanza on the entire creative work'. ${ }^{8}$ When that final scene lasts an average of 8 years, one can reasonably fear that it will obscure the path of one's life.

Dennis R Cooley makes a Kantian version of this argument, claiming that a rational person has an obligation to protect her rationality while it remains in her power to do so. 'In the cases of those who will be demented, it is a rational duty to die physically before dying morally. The moral agent should select selfinflicted death before she becomes incompetent because she owes it to herself as a moral agent. Her action would show that if she could not be a person, then she would not settle for a lower moral status she could prevent." (Unlike Cooley, I argue only that it is ethically defensible, not obligatory, to end one's life in the face of impending incompetence, nor am I convinced that individuals with dementia are non-persons.) 


\section{THE PREDICTIVE CHALLENGE}

In 1999, I argued that genetic testing for dementing diseases such as Huntington and Alzheimer could be appropriate pieces of a plan by people who believed that rational suicide was the right response for them, to a finding of probable future dementia. ${ }^{10}$ At that time, however, the barriers to such a plan were huge, with the largest problem being the difficulties of prediction.

First, one had to rely on health professionals to perform the tests and give the recipients the results. Many clinics were reluctant to do that for people who were honest about their interest in using the results to plan their demise. ${ }^{11}$ This paternalistic attitude persists. For example, Erynn Gordon, the director of genetic counselling at the Coriell Personalised Medicine Collaborative expressed concern that:

\begin{abstract}
...some risk predictions offered by direct-to-consumer genetics firms are associated with conditions for which consumers might not be able to take any action.... This raises the question of whether taking some tests 'can cause more harm than good'. ... That suicides were associated with genetic testing for the incurable and untreatable disease, explains Gordon, led to requirements that anyone seeking testing for Huntington's must first receive a psychiatric assessment. ${ }^{12}$
\end{abstract}

This very notion that there is 'nothing one can do' in response to a disease discounts and disrespects the option of rational suicide.

There have been research studies for some time on the genetic bases of $\mathrm{AD}$, but most make it clear that subjects would not be learning their individual results. ${ }^{13}$ In fact, in the late 1990s, the pleiotropic nature of apolipoprotein E4 (APOE4; conferring increased risk for cardiac disease and dementia) was a favourite dilemma for bioethicists, since most people assumed that it was beneficial to tell people of their increased cardiac risk, given available medication and lifestyle changes, but 'medically useless and socially harmful' to reveal an increased risk for AD. ${ }^{14}$ The Risk Evaluation and Education for Alzheimer's Disease (REVEAL) studies, which purportedly show that it is 'safe' to tell subjects their APOE status, ${ }^{15}$ excluded persons who admitted on the initial questionnaire that planning a possible suicide was one reason they sought to discover their genetic risk. $^{\mathrm{i}}$

Second, for most people, genetic information can merely convey the degree of risk; it cannot definitively predict the disease. Exceptions are Huntingdon disease (HD) and CADASIL ('cerebral autosomal dominant arteriopathy with subcortical infarcts and leukoencephalopathy'), dementing diseases that are $100 \%$ penetrant (if you have the gene, you will get the disease, unless you die first from some other means), and early-onset, familial AD. But 'garden variety' AD, termed 'sporadic' or 'late-onset' $\mathrm{AD}$, which is what most people are concerned about, can never be completely predicted. Sporadic AD results from a complex interaction of genes and environment, which we are only beginning to understand. Even those people who have 2 APOE4s, with a 10-fold increase in risk, have some chance of escaping the disease. ${ }^{16}$ Thus, one must balance the risk of becoming demented against the risk of unnecessarily cutting one's life short, all within a context of substantial uncertainty. However, AD is believed to affect $5 \%$ to $10 \%$ of North Americans aged 65 and older, and $30 \%$ to $50 \%$ of persons by

iI was a study subject in REVEAL, at the Case Western Reserve University site. the end of their ninth decade. ${ }^{13}$ According to the Alzheimer's Association, one-third of 'seniors' in America dies with some form of dementia. ${ }^{17}$ So even for those of us without the 'bad' APOE4, the likelihood of getting AD is not trivial. ${ }^{\mathrm{ii}}$

Third, people who wish to end their life rather than undergo the long decline of dementia face a unique 'Catch-22' situation. Someone with cancer can plan to live as long as life remains worthwhile, and then end her life when the pain or disability overwhelms what made life satisfying. In some countries, and in parts of the USA, one can even receive assistance in doing so. But for someone who anticipates dementia, it is difficult to find the right moment. Commit suicide too early, and one misses out on some precious good years. Wait too long, and the forgetfulness and loss of executive function that characterise even the early stages of the disease can foil one's intentions.

Ironically, the very fact that one has dementia can block one's awareness that one has dementia. I remember my mother speaking with pity and exasperation about a mutual acquaintance who 'didn't know what's what' and who asked the same question over and over again; my mother showed no awareness that she herself did the same thing. As Stephen Latham (2010) describes his father:

It is pretty plain to all of us that my dad of, say, 6 years ago would not have wanted to live like this. But subjectively, as he is now, he is perfectly happy. And there was never an appropriate moment for an intervention, never a time at which to stop his evolution from being the guy who would not have wanted to live like this to becoming the guy who's perfectly happy in this diminished state. Neither a living will nor a durable power of attorney are yet even relevant to his condition, but already all of his former self's interests have been defeated. The preservation of our pristine memories of the person that he once was, his sense of dignity, the thread of his life: all of that is already gone. And all we can do now is wait for it to get worse. ${ }^{2}$

\section{THE DISRESPECTERS}

The predictive conundrum is related to a major challenge for those of us who believe that suicide can be a rational response to a diagnosis of impending dementia. The same 'Catch-22' that can derail one's plans for suicide, can also block access to the avenues in which contemporary society does allow for some expression of autonomy. In Oregon and Washington, for example, doctor assistance in suicide is only available to those who are of sound mind and have less than 6 months to live. The head of Dignitas, a Swiss organisation that has helped more than 1000 people die, claims that suicide is the last human right', and should be available even to those who are physically healthy, but only to those who have 'the capacity of discernment'. ${ }^{18}$ So, to put it bluntly, one wishes to end one's life because one is demented, but one cannot and may not end one's life because one is demented. ${ }^{\text {iii }}$ Parens remarks on the

ii I am aware that the eminent dementia researcher Peter Whitehouse (The Myth of Alzheimer's. New York, NY, USA: St. Martin's Press; 2008) is sceptical even of the existence of Alzheimer Disease. We may indeed find out that the story is much more complex and that 'Alzheimer' was just a way of describing a cluster of symptoms, of varying aetiologies. Nonetheless, it appears clear that having certain genetic traits makes one more likely to become demented.

iii Discussion of euthanasia of demented persons in response to an advance directive, appears to be a more acceptable topic of discussion in parts of Europe, for example, The Netherlands and Belgium, than in North America, presumably because euthanasia itself is more accepted (Gastmans C, J De Lapeliere. Living to the bitter end? A personalist approach to euthanasia in persons with severe dementia. Bioethics 
difficulty the Dutch are having in using criteria for assisted suicide, originally developed for people with cancer, in the context of AD.

[T]hose criteria may have a somewhat odd result. A patient with Alzheimer's disease can easily meet the conditions in the early stage of the disease, when one usually has the mental capacity to request assistance in dying and to make the case that one's existential suffering is unbearable. If one is in the late stage, though, it can be much harder to get such assistance because one does not have that capacity. ${ }^{19}$

One might at this point give up, accept that one may be overtaken by dementia, but depend on a strong advance directive to shorten the course of one's final years by refusing, for example, antibiotics for pneumonia. Foiled again. A group of legal scholars and bioethicists argue that, in cases of dementia, advance directives ought not necessarily to be respected. Allen Buchanan, ${ }^{20}$ Rebecca Dresser, ${ }^{21}$ John Robertson ${ }^{22}$ and others argue that advance directives 'lack the full moral force of contemporary choices' ${ }^{23}$ and that respect for precedent autonomy is misdirected or downright unethical. This question has engendered a complex and rich debate, including vigorous disagreement by such scholars as Norman Cantor ${ }^{24}$ and Ronald Dworkin. ${ }^{8}$ The core of the argument revolves around the undeniable change in personality, and arguably even identity, between the competent person who executed the directive and the incompetent person who will be affected by it. Although everyone agrees that a dramatic change has taken place, they disagree on the ethical and legal meaning of that change. ${ }^{\text {iv }}$ Those who wish to downplay or discount precedent autonomy make two kinds of arguments.

First, they argue that even though personal identity may be maintained, choices made by an individual while competent may not be in accord with her later interests as an incompetent person. The interests in autonomy and independence that drove the competent person to execute the directive, may be quite meaningless to the incompetent person, whose interests may be in having a friendly staff, a cuddly pet, or a favourite dessert.

Second, they argue that the identities of some incompetent persons have changed so radically from that of their former, competent selves that it can no longer be said that the Jane Jones who wrote a directive in 2005 is the same Jane Jones who in 2012 is institutionalised and incompetent. If Jane I is a different person than Jane II, it makes little sense to allow Jane I's wishes to govern what happens to Jane II, especially if they go against Jane II's presumed interests in continuing a life of 'pleasant senility'.

From this radical change in identity, Dresser draws two conclusions. ${ }^{25}$ First, she argues against the concern for individual autonomy expressed by our legal system in addressing issues at

2009;24:78-86). In Finland, 48\% of the general public (but fewer health professionals) found euthanasia of demented persons who had requested euthanasia in their advance directive, to be acceptable (Ryannen O-P. Attitudes toward euthanasia among physicians, nurses, and the general public in Finland. Pub Health 2002;116:322-331.)

${ }^{\text {iv }}$ An interesting variation on this theme is expressed in a letter to the New York Times on the tragedy of Alzheimer disease from the perspective of family members. One woman wrote that, in the 9 years since her husband's diagnosis, coping with dementia has become emotionally more easy. 'One coping strategy...is to view him as my second husband (the first being his former self). I am happier thinking of him as a recent addition to the family than as the man I married 30 years ago'. (Cooper, ME. Reply all. New York Times Magazine, September 23, 2012:8.) the end of life. Instead of trying to figure out what Jane II would have wanted when she was Jane I, if she could have foreseen herself as Jane II, Dresser urges that we accept the impossibility of that task and concentrate instead on making decisions that best respect the person Jane is now, and that put her current interests centre stage. Second, because there is no reason to assume that Jane I's advance directive is the best indicator of Jane II's current interests, there is little reason to respect an advance directive when the course it commands harms Jane II. Thus Dresser and Whitehouse deplore the "near-obsession with defending the competent person's right to control her future treatment', and the 'disproportionate attention' given to the demented person's former concerns. ${ }^{26}$

Although the arguments against precedent autonomy are unpersuasive to many, including me, they are not easy to refute. If Dresser and the others are correct-or if they are able to persuade enough judges, doctors and policymakers of their perspective-then society will not feel obligated to honour advance directives that shorten the lives of 'pleasantly senile' persons by refusing life-sustaining medical interventions. Buchanan believes that this view is already influential enough that 'the threat it appears to pose to advance directives ought to be taken seriously'. 20 Indeed, the President's Council on Bioethics embraced this view, as part of its general discounting of the value of autonomy. In keeping with the overall conservative views of the Council, ${ }^{27}$ its report Taking Care noted that, 'Living wills make autonomy and self-determination the primary values at a time of life when one is no longer autonomous or self-determining, and when what one needs is loyal and loving care. This paradox is at the heart of the trouble with this approach to caregiving'. ${ }^{3}$ The Council went on to declare that:

Even if the law allows it, there are strong moral reasons not to aim at our own death or to ask others to help end our lives by willful acts. Even a competent person's wishes should be limited by such moral boundaries and considerations, because sometimes one's own wishes do an injustice to the value of one's own life, or to the concerns of one's loved ones, or to the norms of the broader society. Our lives are intertwined with others, who are affected powerfully by our choices, and who are themselves conscience-bound moral agents. Our caregivers are not obligated to execute our wishes if those wishes seem morally misguided. ${ }^{3}$

To which Carol Levine acerbically replied, in a review of the Report, 'The President's Council on Autonomy: Never Mind!' 'Although its title suggests a broader analysis, the Report is at heart a sustained critique of individual autonomy and its expression through advance directives when a person has Alzheimer disease or dementia'. ${ }^{28}$

In truth, if one accepts either hypothesis of the school opposed to precedent autonomy, one can arrive at an even stronger conclusion than the one they put forward. Dresser calls directives that limit the lives of future, demented selves a form of 'self-paternalism'. ${ }^{29}$ As in the scene from Still Alice, Jane I is essentially telling the future Jane II that she, Jane I, knows better than Jane II what is in Jane II's best interests. However, the urge to end Jane II's life as quickly as possible does not, I believe, stem primarily from the paternalistic idea that Jane II would be 'better off' dead, assuming that she is indeed pleasantly demented and not suffering. Rather, the motivation is unabashedly selfish. In truth, Jane II's continued existence is a strong threat to Jane I's autonomy-based interests, and if we were to adopt Dresser's view, Jane I is the last person whose opinion on Jane II should be given weight. If Dresser's view becomes the regnant model, persons for whom autonomy and 
independence are important values, if they are at high risk for dementing diseases, would do well to consider pre-emptive suicide.

In sum, if Dresser et alia are right, then the person I will become, should I develop dementia, will be someone radically disconnected from my former self, so much so that there is no justification for taking my present wishes, as expressed in an advance directive, as dispositive for decision making about the person I will become. My body will have been taken over by another person with a disturbing but illusory resemblance to my former self. Legally and socially, this new being will have a very strange connection to my former self. She will retain my name and Social Security number, she will be able to use up my assets and wear my clothes, and my spouse will not be free to remarry, but she will not legally be me when it comes to honouring my advance directives. Former friends and relatives will think of that person as me, may well persist in visiting her despite the fact that she does not remember them, and thus will have their memories of me distorted by the existence of this woman. Yet the values and interests I expressed to family and friends when competent will be discounted as largely irrelevant. For the autonomy-oriented person who accepts Dresser's arguments, a diagnosis of impending dementia is a warning that one is about to be invaded by an enemy army that will always win. It is entirely sensible to burn down the fort and refuse it a home.

Another argument put forward against respecting precedent autonomy is the unfair burden it puts on caregivers and professionals. Imagine the nurse or doctor who meets for the first time a pleasant, cheerful, demented person, and is then told not to give that person antibiotics for an entirely treatable pneumonia because of the directive of the prior, competent person whom she has never met. Dresser argues that a 'constellation of values', including compassion and empathy for dependent persons, requires that prior directives be ignored if following them would cause 'harm' to vulnerable patients. ${ }^{30}$ (Of course, some of us who are, in Dresser's perspective, 'obsessed' with autonomy, might parse terms such as harm and empathy differently, and see ourselves as 'vulnerable' precisely because we no longer have the ability to end our lives.) Here again, ending one's own life before putting that difficult burden on others, seems the essence of good sense.

Thus, the confluence of barriers to having one's precedent autonomy respected highlights the importance of being able to make reasonable predictions of risk and to have some advance notice of impending dementia, so as to take one's destiny into one's hands.

\section{THE PREDICTIVE CHALLENGE (PARTIALLY) SOLVED}

Taking one's life into one's own hands is the most realistic option for people for whom a life with dementia is unacceptable. Yet until recently, as we saw above, a person interested in rational suicide to avoid probable dementia faced serious information hurdles, making prediction difficult. Today, however, many of these barriers have been breached, if not completely dismantled.

First, one no longer needs to rely on clinics and health professionals to order and interpret the relevant tests, at least not the initial genetic tests. Direct-to-consumer genetic testing is increasingly available and affordable. As one example, for $\$ 99$, 23 andMe will test you for a number of traits including APO in a Clinical Laboratory Improvement Amendments (CLIA)-certified laboratory. 23andMe's educational materials are sophisticated, and genetic counselling is available (for additional cost). You don't have to explain why you are interested, or get into a philosophical argument with your doctor over the meaning of life and why you would prefer death to AD. You just do it.

Second, it is now becoming increasingly possible to diagnose $\mathrm{AD}$ through laboratory tests, which can give more specificity to the genetic tests and also track the disease progression even before symptoms are manifest. As we saw above, even the unfortunate finding of one or two APOE4s in your genetic blueprint cannot tell you definitively whether you will get the disease, nor can it tell you when the disease will strike. Thus, even a decade ago, one was faced with the dilemma of losing some good years versus missing the window of opportunity. Now, however, we are seeing an explosion of research looking for ways to diagnose $\mathrm{AD}$ and HD presymptomatically.

The Alzheimer's Association explains that, in 2011, the Association and the National Institute of Aging put forward draft guidelines and criteria that represent a paradigm shift in the diagnosis of AD. Current (1984) criteria rely primarily on a doctor's clinical judgment, based on reports from family and friends, cognitive tests and general neurological assessment. The new proposed criteria incorporate two 'notable' changes. First, $\mathrm{AD}$ is now seen as a three-stage disease, of which the first stage 'occurs before symptoms develop'. Second, the new criteria incorporate biomarkers, biological factors that can indicate the presence of disease, or the risk of developing a disease. In the preclinical stage, 'individuals have measurable changes in the brain, cerebrospinal fluid and/or blood (biomarkers) that indicate the earliest signs of disease, but they have not yet developed symptoms such as memory loss. This preclinical or presymptomatic stage reflects current thinking that Alzheimer-related brain changes may begin 20 years or more before symptoms occur'. ${ }^{31}$

Current efforts to diagnose $\mathrm{AD}$ in the presymptomatic stage are driven by three different goals. First, an 'early warning system' could help with individual long-range planning (although only Parens and Johnston acknowledge that longrange planning could include pre-emptive suicide). ${ }^{17}$

Second, finding the disease at the earliest possible stage identifies appropriate patients for treatments that could slow the course of the disease. The US Food and Drug Administration (FDA) has acknowledged a category of 'preclinical AD' where 'only subtle cognitive deficits are present in the absence of any detectable functional impairment'. ${ }^{32}$ This leads to the third point, which is that presymptomatic diagnosis is a crucial building block in medical research that seeks to find and test those very treatments. ${ }^{33}$

Presymptomatic testing runs a gamut that includes neuroimaging to track volume loss and cerebral blood flow in the brain, ${ }^{16}$ concentrations of amyloid- $\beta$ in the cerebral spinal fluid, ${ }^{33}$ a molecular test based on plasma signalling proteins, ${ }^{34}$ noninvasive tests of episodic memory ${ }^{35}$ and self and informant reports of cognitive status. ${ }^{35}$ Modalities range from invasive, unpleasant and expensive (lumbar puncture) to a simple pen and paper test. In one study, compared to older adults who escaped dementia, those who later developed $\mathrm{AD}$ performed more poorly across a spectrum of neuropsychological measures, including attention; verbal learning and memory; executive function; processing speed; language. ${ }^{16}$ A study on HD was able to predict the onset of disease through MRI in people known to have the gene. ${ }^{36} \mathrm{~A}$ research project at the Oregon Center for Aging and Technology ${ }^{\mathrm{v}}$ is based on the hypothesis that 'automatic, continuous monitoring of linguistic behaviour has the

${ }^{\mathrm{v}}$ See http://www.orcatech.org/research/studies/developing-automated-emailmonitoring-technology-for-detecting-cognitive-decline. 
potential to serve as a first line of action in detecting onset of decline'. The research aims to 'build and test a software package that will extract useful information about cognitive health of email users by monitoring the linguistic features embedded within email messages...'. Eric Dishman of Intel, in a recent TEDTalk, demonstrates research to use ordinary telephones to support and monitor the mental and physical health of people who are aging at home:

Because that moment when you answer the phone is a cognitive test every time you do it... And as we monitor phone usage by seniors over a long period of time, down to the tenths of a microsecond, that recognition moment of whether they can figure out that person on the other end is a friend and we start talking to them immediately, or they do a lot of what's called trouble talk, where they're like, 'Wait, who is this? Oh.' Right? Waiting for that recognition moment may be the best early indicator of the onset of dementia than anything that shows up clinically today. ${ }^{\mathrm{vi}}$

Other possibilities include motion sensors and 'smart carpets' that monitor gait and mobility for early signs of cognitive decline. These monitoring systems are part of a general movement to help older people age 'successfully' at home, with results being transmitted to watchful family members or clinics, but there is no reason a savvy and determined person could not make use of these to direct information only to herself.

These advances do not, of course, obviate the Catch-22 of $\mathrm{AD}$, but they do make it possible to take evasive action, thus ending one's life before it is taken over by some 'pleasantly demented' second self.

\section{CONCLUSIONS}

Critics may argue that these various tests should not be opened up to people until they are completely predictive, or perhaps never. Karlawish worries that the results of biomarker testing 'are potentially harmful knowledge' that can lead recipients to develop 'anxiety or depression or even become suicidal'. ${ }^{37} \mathrm{He}$ argues that subjects of research studies do not have to be told their results, as information derived from biomarkers does not provide 'meaningful information for care', presumably in the absence of effective drugs or lifestyle changes, but he acknowledges that as research progresses to trials that enrol only participants who meet criteria for preclinical $\mathrm{AD}$, it will be impossible to keep subjects uninformed about their risk status. Of course, some of us might disagree with Karlawish as to what constitutes 'meaningful information'. In the absence of 'care', some of us might find that information valuable to effect our exit strategy.

At this point neither the underlying genetic blueprint, nor the various presymptomatic tests, are $100 \%$ informative. However, in the future it is possible that the results of a variety of genetic, clinical and biomarker tests, each with a substantial freight of information, can be interpreted to come closer to certainty. It is important to remember that we are dealing with two different but related types of information. The first expresses risk, that is, the probability that one will get a dementing disease. The second expresses immanence, or how near one is to approaching the danger point where one will no longer be able to act. The degree of certainty one needs in order to act is, obviously, a matter of individual values. One must weigh the value of, for example, more years of life as an older and probably demented

\footnotetext{
${ }^{\text {vi }}$ See http://www.ted.com/talks/eric_dishman_take_health_care_off_the
} mainframe.html person against the value of not becoming demented. People have been making these kinds of probabilistic judgments for a long time. Women, for decades, have been weighing the likelihood of having a child with Down Syndrome versus the likelihood of a miscarriage due to amniocentesis, against the background of varying risks due to age, run through the prism of their own attitudes towards the benefits and burdens of having a child with Down. Patients with cancer balance the possible benefits of various treatments (many of them experimental) against their serious side effects, including the risk of cardiac damage and second cancers in later life. Women who carry the BrCa mutation are urged to consider prophylactic bilateral mastectomy, despite the fact that $\mathrm{BrCa}$ is not $100 \%$ penetrant and that mastectomy does not guarantee that one will not get breast cancer. This is no different. Death is irreversible, but so is dementia. People must weigh the risks of shortening their lives unnecessarily against the risks of developing $\mathrm{AD}$ and living as long as 20 years with dementia. The risks are, by their very definition, uncertain, but that should not bar people who wish to do so from getting all the information available and acting on their own values.

Acknowledgements The author thanks Barbara Bernhardt, Sharona Hoffman, Jason Karlawish, an anonymous reviewer, and the CIGHT group at University of Pennsylvania, for helpful comments on earlier versions of this paper.

Funding This work was partially supported by PennCIGHT through grant P5OHG004487 from the National Human Genome Research Institute at the National Institutes of Health.

\section{Competing interests None.}

Provenance and peer review Not commissioned; externally peer reviewed.

\section{REFERENCES}

1 Genova L. Still alice. New York: Pocket Books, 2009:270-1.

2 Latham SR. Living wills and Alzheimer's disease. Quinnipiac Probate Law J 2010:23:425-31.

3 President's Council on Bioethics. Taking care: ethical care-giving in our aging society. Washington, DC: President's Council on Bioethics, 2005:16.

4 McKibbin $\mathrm{CL}$, Walsh W, Rinki $\mathrm{M}$, et al. Lifestyle and health behaviors among female family dementia caregivers: a comparison of wives and daughters. Aging Ment Health 1999:3:165-72.

5 Wolff M. A life worth ending. New York Magazine. 2012. http://nymag.com/news/ features/parent-health-care-2012-5/.

6 Meilaender G. I want to burden my loved ones. First Things, 1991;16:12-14.

7 Hardwig J. Is there a duty to die? Hastings Cent Rep 1997:27:34-42.

8 Dworkin R. Life's dominion: an argument about abortion, euthanasia, and individual freedom. New York: Alfred A. Knopf, 1993:199.

9 Cooley DR. A Kantian moral duty for the soon-to-be demented to commit suicide. Am J Bioeth 2007:7:37-44.

10 Davis DS. Rational suicide and predictive genetic testing. J Clin Ethics 1999;10:316.

11 DeGrazia D. The ethical justification for minimal paternalism in the use of the predictive test for Huntington's Disease. J Clin Ethics 1991;2:219-28.

12 Udesky L. The ethics of direct-to-consumer genetic testing. Lancet 2010:376:1377-88.

13 Schipper HM. Presymptomatic apoliprotein E genotyping for Alzheimer's disease risk assessment and prevention. Alzheimer Dementia 2011;7:e118-23.

14 Wachbroit R. The question not asked: the challenge of pleiotropic genetic tests. Kennedy Inst Ethics J 1998:8:131-44

15 Green RC, et al. 2009 Disclosure of APOE genotype for risk of Alzheimer's Disease. N Engl J Med 2009;361:245-54.

16 Twamley W, Legendre Ropack SA, Bondi MW. Neuropsychological and neuroimaging changes in preclinical Alzheimer's disease. J Int Neuropsychol Soc 2006:12:707-35.

17 Alzheimer's Association. 2013 Alzheimer's disease facts and figures. http://www.alz. org/downloads/facts figures 2013.pdf (accessed 30 Mar 2013).

18 Foulkes I. Dignitas boss: healthy should have right to die. BBC News Europe 2010. http://www.bbc.co.uk/news/10481309

19 Parens E. Field notes: Alzheimer's disease and personhood. Hastings Cent Rep 2013:43:inside cover.

20 Buchanan A. Advance directives and the personal identity problem. Philos Public Aff 1988; 17:277-302

21 Dresser RS. Dworkin on dementia: elegant theory, questionable policy. Hastings Cent Rep 1995;25:32-8.

22 Robertson JA. Second thoughts on living wills. Hastings Cent Rep 1991:21:6-9. 
23 Kadish SH. Letting patients die: legal and moral reflections. California Law Rev 1992;80:857-88.

24 Cantor NL. Prospective autonomy: on the limits of shaping one's postcompetence medical fate. J Contemp Health Law Policy 1992;8:13-48.

25 Dresser RS. Missing persons: legal perceptions of incompetent patients. Rutgers Law Rev 1994;46:609-719.

26 Dresser RS, Whitehouse PJ. The incompetent patient on the slippery slope. Hastings Cent Rep 1994;24:6-12.

27 Green RM. 2010 The President's council on bioethics: requiescat in pace. J Religious Ethics 2010;38:197-218.

28 Levine C. President's council on autonomy: never mind! Hastings Cent Rep 2006;36:46-7.

29 Dresser RS. Advance directives, self-determination, and personal identity. In Hackler C, Moseley R, Vawter DE.eds Advance directives in medicine. New York: Praeger, 1989:155-70.

30 Dresser RS. Precommitment: a misguided strategy for securing death with dignity. Texas Law Rev 2003;81:1823-47.

31 Parens $\mathrm{E}$, Johnston J. As tests to predict Alzheimer's emerge, so may debates over the right to die. Time.com 2011. http://healthland.time.com/2011/06/08/ as-tests-better-predict-alzheimers-patients-may-contemplate-their-right-to-die/ (accessed 29 Mar 2013).

32 US Food and Drug Administration, Guidance for Industry: Alzheimer's Disease: Developing Drugs for the Treatment of Early-Stage Disease: Draft Guidance (for comment purposes only), February 2013. http://www.fda.gov/downloads/Drugs/ GuidanceComplianceRegulatoryInformation/Guidances/UCM338287.pdf (accessed 29 Mar 2013).

33 Bateman RJ, Xiong C, Benzinger TL, et al. Clinical and biomarker changes in dominantly inherited Alzheimer's Disease. N Engl J Med 2012;367:795-804.

34 Ray S, Britschgi M, Herbert C, et al. Classification and prediction of clinical Alzheimer's diagnosis based on plasma signaling proteins. Nat Med 2007;13:1359-62.

35 Rabin LA, Wang C, Katz M, et al. Predicting Alzheimer's Disease: neuropsychological tests, self-reports, and informant reports of cognitive difficulties. J Am Geriatr Soc 2012;60:1128-34.

36 Keuhn BM. Imaging helps to identify early changes associated with Huntington Disease. JAMA 2011;305:138.

37 Karlawish J. Addressing the ethical, policy, and social challenges of preclinical Alzheimer disease. Neurology 2011;77:1487. 